\title{
Evaluation of three methods of suture for skin closure in total knee arthroplasty: a randomized trial
}

Rodrigo Barreiros Vieira, Gustavo Waldolato*, João Sequeira Fernandes, Thiago Gontijo de Carvalho, Pedro Augusto Maciel Moreira, Guilherme Barbosa Moreira and Jorge Suman Vieira

\begin{abstract}
Background: There are several studies comparing techniques and different materials, yet the results are not unanimous. We compared three methods of skin closure in total knee arthroplasty (TKA), including suture with single stitches and unabsorbable MonoNylon ${ }^{\oplus}$, as well as continuous subcuticular suture with Monocry ${ }^{\circledR}$ or barbed Stratafix ${ }^{\oplus}$ absorbable suture.

Methods: A prospective, randomized study was conducted with 63 patients undergoing TKA between March 2016 and December 2016. Patients were divided into three groups: traditional suture MonoNylon ${ }^{\circledast}$ (n 22), subcuticular continuous suture with Monocry $\mathbb{1}^{\oplus}$ (n 20), and another barbed with Stratafix ${ }^{\oplus}$ (n 21). The closure time, length of wire used, pain intensity, possible complications, and cosmeses were evaluated.

Results: Subcuticular continuous suture using Monocry ${ }^{\circledR}$ was superior to traditional suture using MonoNylon ${ }^{\oplus}$ as less thread was used ( $p$ 0.01) and a better cosmetic effect was achieved $(p<0.01)$, which was equal to Stratafix ${ }^{\otimes}$ aspects analyzed $(p>0.05)$. Complications were observed mostly in patients who used Stratafix ${ }^{\circledast}$.

Conclusions: This study concluded that the subcuticular suture with absorbable monofilament Monocryl ${ }^{\circledR}$ proved to be advantageous compared to the others because it presented results equal to the barbed Stratafix ${ }^{\varpi}$, however with fewer complications. Furthermore, Monocryl ${ }^{\circledR}$ was shown to be equal or superior to traditional MonoNylon ${ }^{\circledR}$ suture regarding in relation pain intensity, aesthetic result, and effective cost.
\end{abstract}

Trial registration: WHO ICTRP identifier RBR78dh5d. Retrospectively registered: 07/29/2020.

Keywords: Total knee arthroplasty, Suture, Skin closure

\section{Background}

Total knee arthroplasty (TKA) is increasingly performed for the treatment of symptomatic gonarthrosis, with a projection of more than $600 \%$ increase in the number of surgeries in less than three decades and an expectation of 3.5 million annual procedures by 2030 in the United States [1]. This rapid increase in the number of surgeries

\footnotetext{
* Correspondence: gwaldolato@hotmail.com

Department of Orthopaedics, Hospital Universitário Ciências

Médicas-Faculdade de Ciências Médicas de Minas Gerais, Rua dos Aimorés,

2896- Santo Agostinho, MG 30140-073 Belo Horizonte, Brazil
}

is due to the aging of the population and to the excellent results achieved by TKA, leading to rates close to $90 \%$ of satisfaction according to patients [2]. To a large extent, the improvement in the positive results is related to a better understanding of the biomechanics of the knee, to the improvement of the components of the prosthesis, and also to the technique used in all stages of the surgical procedure, including the closure of the skin.

Various materials can be used for skin closure by means of different techniques, with the purpose of minimizing complications such as scar pain, dehiscence, and

C C The Author(s). 2021 Open Access This article is licensed under a Creative Commons Attribution 4.0 International License, which permits use, sharing, adaptation, distribution and reproduction in any medium or format, as long as you give appropriate credit to the original author(s) and the source, provide a link to the Creative Commons licence, and indicate if changes were made. The images or other third party material in this article are included in the article's Creative Commons licence, unless indicated otherwise in a credit line to the material. If material is not included in the article's Creative Commons licence and your intended use is not permitted by statutory regulation or exceeds the permitted use, you will need to obtain permission directly from the copyright holder. To view a copy of this licence, visit http://creativecommons.org/licenses/by/4.0/ The Creative Commons Public Domain Dedication waiver (http://creativecommons.org/publicdomain/zero/1.0/) applies to the data made available in this article, unless otherwise stated in a credit line to the data. 
infections, besides reduction in surgical time and aesthetic improvement. Stitching with simple suture and use of unabsorbable suture is the most widespread method since it is the simplest and has a low cost. Other techniques such as subcuticular suture, with unabsorbable or absorbable suture, and closure with staples are described and widely used in practice [3]. In the literature, there are several studies comparing techniques and different materials [4-6], yet the results are not unanimous.

In recent years, the barbed wire closure presents as a new option, with the justification of less time spent and cosmetic improvement of the scar. These threads increase the ability to approach and maintain the edges in soft tissues, minimizing episodes of dehiscence, in addition to avoiding the need for nodes, consequently visually improving the scar. The barbed wire suture has been accepted in plastic surgery [7], gynecology [8], urology [9], and general surgery. In the field of orthopedics, Gililland et al., in 2012, presented slightly favorable results with the use of this material in the closure of the TKAs in comparison with suture with simple points [10]. Positive findings were also found by other researchers [11]. However, other studies have not demonstrated the superiority of this method in comparison to others, especially its safety, leading to doubts as to its use in TKAs [12-14].

The present study aimed to compare three methods of skin closure in TKA, namely suture with single suture using unabsorbable MonoNylon ${ }^{\circ}$, as well as continuous subcuticular suture with Monocryl $^{\circ}$ absorbable or Stratafix ${ }^{\circ}$ barbed.

\section{Methods}

This is a prospective, and randomized study including patients who underwent TKA at the University Hospital in Brazil between March 2016 and December 2016.

All patients with gonarthrosis treated at the knee surgery outpatient clinic of the University Hospital participated in the study. The inclusion criteria were as follows; patients with primary or secondary gonarthrosis with indication of TKA, aged 45 to 85 years, both sexes. Patients with previous history of knee surgery, patients with inflammatory joint diseases, smokers (at least 1 cigarette per day (2)), alcoholics (consumption of 15 doses / week for men and 10 doses / week for women (1)), with hypoalbuminemia (below $3.5 \mathrm{mg} / \mathrm{dl}$ (3)), and anemia (hemoglobin $\leq 10 \mathrm{mg} / \mathrm{dl}$ ) were excluded. Of the 68 patients who met the inclusion criteria, five were excluded, leaving 63 patients in the study.

Participants were evaluated at the institution's knee surgery outpatient clinic. In this analysis, demographic data (sex, age, laterality, body mass index [BMI]) were collected and randomized by draw of a sealed brown envelope containing three cards referring to each of the groups: group 1 (single suture), 22 patients underwent single-stitched interrupted sutures and use of monofilament monofilament MonoNylon ${ }^{\circ}$ 3-0 (Ethicon ${ }^{\circ}$, Johnson \& Johnson); group 2 (intradermal suture), 20 patients underwent continuous intradermal suture with monofilament absorbable monofilament Monocryl $^{\circ}$ Polytechnique 25) 3-0 (Ethicon', Johnson \& Johnson); and group 3 (barbed wire suture), 21 patients underwent continuous intradermal suture using Stratafix ${ }^{\circ}$ unidirectional PGA-PCL barbed monofilament barbed wire (Ethicon ${ }^{\circ}$, Johnson \& Johnson). The surgical procedures were scheduled up to 2 weeks after randomization by sealed envelope. One of the researchers (GW) was responsible for randomization and another researcher (GBM) enrolled participants.

The preparation of the surgical procedure, including antibiotic therapy (Cephalosporin $1^{\circ}$ generation) $30 \mathrm{~min}$ before anesthetic induction and anesthesia (spinal anesthesia + sedation) was uniform for all patients, according to the routine of service. A pneumatic tourniquet was used in all patients, besides an anterior incision $17 \mathrm{~cm}$ long, with access to the joint cavity by medial parapatellar arthrotomy, eversion, and lateral dislocation of the patella.

After implantation of all components of the prosthesis (Modular $\mathrm{III}^{\circ}, \mathrm{MDT}, \mathrm{Brazil}$ ), closure of the arthrotomy with absorbable interrupted suture Vicryl $^{\circ} 0$ (Ethicon ${ }^{\circ}$, Johnson \& Johnson) and of the subcutaneous tissue with absorbable interrupted suture Vicryl ${ }^{\circ} 2.0$ (Ethicon ${ }^{\circ}$, Johnson \& Johnson), the skin was sutured using the technique defined by prior randomization. All surgical procedures were performed by the same surgeon (RBV). The skin closure was performed with the knee in extension, in a unidirectional direction from proximal to distal. The beginning of the skin closure until its term was timed the time spent in making the suture and at the end, the length of thread used was gauged.

The incision was dressed with sterile gauze and Micropore surgical tape ( $3 \mathrm{M}$ Company). The dressing were changed daily for 14 days and then removed.

The postoperative procedures of analgesia, anticoagulation, antibiotic therapy, hospital discharge, dressing method and wound care and guidelines were also the same for all.

Patients were reevaluated for this study after 2 and 12 weeks in terms of wound pain intensity according to the visual analogue scale (where $10=$ maximum intensity pain and $0=$ no pain) and changes in wound healing (infectious, allergic signs, and dehiscence). Additionally, in the 12th week, patients were evaluated for the cosmesis degree of the scar according to the Stone Brooks Scar scale for surgical wound cosmesis [15] (Table 1). 
Table 1 Stony Brook Scar Evaluation Scale

\begin{tabular}{|c|c|c|}
\hline Scar category & & Points \\
\hline \multirow[t]{2}{*}{ Width } & $>2 \mathrm{~mm}$ & 0 \\
\hline & $\leq 2 \mathrm{~mm}$ & 1 \\
\hline \multirow[t]{2}{*}{ Height } & Elevated/depressed in relation to suronding skin & 0 \\
\hline & Flat & 1 \\
\hline \multirow[t]{2}{*}{ Color } & Daker than surrounding skin & 0 \\
\hline & Same color or light than surrounding skin & 1 \\
\hline \multirow[t]{2}{*}{ Hatch marks/suture marks } & Present & 0 \\
\hline & Absent & 1 \\
\hline \multirow[t]{2}{*}{ Overall apparence } & Poor & 0 \\
\hline & Good & 1 \\
\hline
\end{tabular}

* Total score sum of individual scores; range, 0 (worst) to 5 (best)

The data were tabulated in Microsoft Excel $^{\oplus}$ and the results were presented in tables and measurements. A descriptive and inferential analysis of the results was performed. To guarantee the accuracy of the comparisons, the homogeneity of the samples was verified using Shapiro-Wilk test. The comparisons were performed using the Tukey test. The variables were analyzed by the $\mathrm{R}$ software through the TukeyHSD function, where the model is the ANOVA. A significance level $\mathrm{p}<0,05$ was considered in all these comparisons.

\section{Results}

In the demographic analysis of the studied sample, $73 \%$ $(n=46)$ of the population was female and $27 \%(n=17)$ was male. The mean age of the patients was 68 years (range: 45-81 years). Regarding BMI, $46.1 \%$ of the patients had a BMI > 30, considered obese, $42.9 \%$ between 25 and 30, considered overweight, and only $11.1 \%$ within the normality index. Demographic data between groups are summarized in Table 2.

\section{Closing time}

Comparing the types of sutures in relation to the time of closure of the skin, it was observed that the unabsorbable simple suture group recorded a time significantly inferior to the others $(p<0.05)$, with a mean of $7.40 \mathrm{~min}$ compared to 8.90 and $9.00 \mathrm{~min}$ in the Monocryl $l^{\circ}$ and barbed Startafix groups, respectively (Table 3).

Table 2 Compared demographic data between groups

\begin{tabular}{|c|c|c|c|c|}
\hline Group & $\mathrm{n}$ & Sex F:M & Age (mean) & $\mathrm{BMI}<2525-30>30$ \\
\hline Simple & 22 & $18: 4$ & 68.95 & 11110 \\
\hline Monocryl $\left.\right|^{\circledast}$ & 20 & $13: 7$ & 69.75 & 3710 \\
\hline Stratafix ${ }^{\circledast}$ & 21 & $15: 6$ & 64.33 & 399 \\
\hline
\end{tabular}

$n$ number of patients $F$ famele $M$ male $B M I$ Body mass index

\section{Wire length used}

Regarding the length of the wire used for suturing the skin, the unabsorbable simple suture required a significantly longer wire length than that used for both the absorbable Monocry $^{\circ}$ and the barbed Stratafix ${ }^{\circ}$ sutures $(p<0.05)$. However, when the barbed and Monocryl $l^{\circ}$ wire groups were compared, no significant difference was observed (Table 4).

\section{Intensity of pain}

Regarding the intensity of pain in the first postoperative evaluation at 2 weeks, the barbed Stratafix $x^{\oplus}$ suture group presented more intense pain when compared to the unabsorbable simple suture group $(p<0.01)$. (Table 5$)$

Regarding the second evaluation at 12 weeks, there was a reduction in pain sensation in all three groups; however, the barbed Stratafix ${ }^{\oplus}$ suture group reported more severe pain. There was no significant difference between the groups $(p>0.05)$.

\section{Analysis of surgical wound cosmesis}

In the evaluation of the surgical wound cosmesis, the mean Stone Brook Scar score of the unabsorbable suture was 1.91 whereas that of the subcuticular Monocryl ${ }^{\circledR}$ and barbed totaled 3.30 and 3.00, respectively. There was a significant difference in the cosmesis score between groups, with Post-hoc tests revealed that a significant difference existed between the unabsorbable suture and Monocryl $l^{\bullet}$ groups as well as between the unabsorbable MonoNylon ${ }^{\bullet}$ suture and barbed Stratafix ${ }^{\bullet}$ suture groups (Table 6).

\section{Complications}

Regardless of the type of suture performed, no patient presented with an allergic reaction to the thread used. In addition, only one patient, who was in the barbed Stratafix $x^{\oplus}$ suture group, presented with a superficial infection. Ten patients had a slight dehiscence, less than $20 \%$ 
Table 3 Analysis of time spent, in minute, on skin closure

\begin{tabular}{|c|c|c|c|c|c|c|c|}
\hline Group & Min. & Max. & Mean & $\pm \mathrm{SD}$ & $95 \% \mathrm{Cl}$ & Group x Group & $p^{1}$ \\
\hline$\overline{\text { Simple }}{ }^{\oplus}$ & 7.03 & 16.00 & 7.40 & 1.88 & [6.61-8.19] & Simple $\times$ Stratafix ${ }^{\oplus}$ & 0.01 \\
\hline Monocryl ${ }^{\circledast}$ & 7.00 & 12.30 & 8.90 & 1.44 & [8.23-9.57] & Monocry ${ }^{\oplus} \times$ Simple & 0.01 \\
\hline Stratafix ${ }^{\circledast}$ & 5.00 & 11.35 & 9.00 & 1.77 & [8.15-9.87] & Stratafix ${ }^{\circledast} \times$ Monocryl $^{\circledast}$ & 0.98 \\
\hline
\end{tabular}

Min. minimum; Max. maximum; SD Standard deviation; Cl Confidence interval

${ }^{1}$ Tukey Test

of the operative wound length, of which four belonged to the subcuticular $M_{\text {Monocryl }}{ }^{\circ}$ suture group and six to the barbed Stratafix ${ }^{\circ}$ suture group. Patients submitted to single closure unabsorbable MonoNylon ${ }^{\bullet}$ did not present with any postoperative complications (Table 7).

\section{Discussion}

All aspects related to TKA are constantly evolving, with the purpose of improving patient satisfaction and reducing complications. In the last decade, many studies have attempted to compare the best mode of cutaneous closure in arthroplasties; however, the heterogeneity of the methods used and the lack of uniformity of the results led to the realization of this prospective and randomized study. The present study showed that there was no difference in the parameters searched between subcuticular sutures, whether with absorbable Monocryl ${ }^{\circ}$ or barbed Stratafix ${ }^{\circ}$ however, they were superior to the suture with simple points, especially regarding the cosmetic aspect.

The present study included mostly female patients, corroborating with other studies on knee arthroplasty $[11,16]$, which was expected due to the higher prevalence of gonarthrosis in women [17]. Also, about half of the patients were obese, who are more likely to have complications in the healing of operative wounds [18]. However, these patients were homogeneously distributed among the evaluated groups, not interfering with the results. The intradermal suture with barbed wire group was composed of patients younger than the other groups ( $p$ 0.01); however, the authors did not believe that the small difference (mean: 5 years younger) influenced the results of the parameters analyzed.

The longer the time spent in surgery increases the morbidity of the procedure; therefore, it is always important to use techniques that minimize surgical time. Following this prerogative, a shorter time spent closing the skin can be of great help. Gililland et al. Reported a significantly shorter closure time with subcuticular suture using Stratafix ${ }^{\circ}$ compared to single suture [10], as did other authors $[16,19,20]$. Smith et al. found that the use of subcuticular suture starting at the center of the wound and directing to the distal and proximal region of the wound made simultaneously by two professionals is a justification for the shorter closure time with subcuticular sutures with Stratafix ${ }^{\circ}$ versus traditional unabsorbable sutures. However, Maheshwari et al. showed that there was no difference in time spent using subcuticular sutures with Stratafix or traditional single stitches in knee arthroplasties [21]. We found that the closure time using simple suture was faster than the subcuticular ones with absorbable Monocryl ${ }^{\circ}$ or barbed Stratatifx ${ }^{\circ}$. However, despite this being statistically significant, on average the time was only about $90 \mathrm{~s}$ shorter, a difference that we considered not to influence the total time of arthroplasty.

The amount of wire used between the three different sutures was found to differ between groups. The continuous subcuticular techniques with either with Monocryl $^{\circ}$ or with Stratafix ${ }^{\circ}$ used on mean a little more than $30 \%$ of the length used in single suturing. However, the specific value of wire used is appreciably lower with the use of MonoNylon and especially Monocryl ${ }^{\circ}$ compared to barbed Stratafix ${ }^{\circ}$, based on the commercial values of each suture in the Brazilian market. The cost of the converted MonoNylon ${ }^{\circ}$ is USD $\$ 0.04 / \mathrm{cm}$ of wire, Monocryl ${ }^{\circ}$ is USD \$0.09 / $\mathrm{cm}$, while the Stratafix is USD $\$ 0.83 / \mathrm{cm}$. Taking into account the average wire used in the study for each technique, $\$ 2.54$ was spent on the skin suture of each patient with $M o n o c r y l l^{\circ}$, \$3.34 per patient with MonoNylon ${ }^{\circ}$ thread, and $\$ 22.68$ per patient with sutures using Stratafix. Ting et al. also showed a significantly higher cost in cutaneous closure with barbed wire compared to control (53 vs. 9 USD, p <

Table 4 Comparison of the length of suture, in centimeter, used between groups

\begin{tabular}{|c|c|c|c|c|c|c|c|}
\hline Group & Min. & Max. & Mean & $\pm \mathrm{SD}$ & $95 \% \mathrm{Cl}$ & Group x Group & $p^{1}$ \\
\hline Simple $^{\circledast}$ & 38.30 & 118.00 & 83.53 & 17.95 & [75.57-91.49] & Simple $\times$ Stratafix ${ }^{\circledast}$ & 0.00 \\
\hline Monocryl $\left.\right|^{\oplus}$ & 19.00 & 48.00 & 28.25 & 8.67 & [24.19-32.28] & Monocryl ${ }^{\oplus} \times$ Simple & 0.00 \\
\hline Stratafix ${ }^{\circledast}$ & 22.00 & 33.00 & 27.33 & 2.69 & [26.11-28.55] & Stratafix ${ }^{\oplus} \times$ Monocry $^{\circledast}$ & 0.35 \\
\hline
\end{tabular}

Min. minimum; Max. maximum; SD Standard deviation; $\mathrm{Cl}$ Confidence interval

${ }^{1}$ Tukey Test 
Table 5 Analysis of pain intensity between groups at 2- and 12-weeks post-operative

\begin{tabular}{|c|c|c|c|c|c|c|c|c|}
\hline Time $^{*}$ & Group & Min. & Max. & Mean & $\pm \mathrm{SD}$ & $95 \% \mathrm{Cl}$ & Group x Group & $\overline{p^{1}}$ \\
\hline & Simple & 0 & 8 & 3.87 & 2.21 & {$[2.88-4.84]$} & Simple $\times$ Stratafix ${ }^{\circledast}$ & 0.01 \\
\hline \multirow[t]{2}{*}{2} & Monocry $\left.\right|^{\otimes}$ & 1 & 10 & 5.25 & 2.40 & [4.12-6.37] & Monocryl ${ }^{\oplus} \times$ Simple & 0.11 \\
\hline & Stratafix ${ }^{\circledR}$ & 3 & 9 & 6.00 & 1.92 & [5.12-6.87] & Stratafix ${ }^{\circledast} \times$ Monocry $^{\circledast}$ & 0.51 \\
\hline \multirow[t]{3}{*}{12} & Simple & 0 & 6 & 2.00 & 1.74 & {$[1.23-2.77]$} & Simple $\times$ Stratafix ${ }^{\circledast}$ & 0.09 \\
\hline & Monocry| $\left.\right|^{\oplus}$ & 0 & 7 & 2.75 & 2.36 & {$[1.64-3.85]$} & Monocryl ${ }^{\circledR} \times$ Simple & 0.53 \\
\hline & Stratafix ${ }^{\circledast}$ & 0 & 9 & 3.48 & 2.58 & {$[2.30-4.65]$} & Stratafix ${ }^{\circledast} \times$ Monocry $^{\circledR}$ & 0.55 \\
\hline
\end{tabular}

Min. minimum Max. maximum SD Standard deviation $\mathrm{Cl}$ Confidence interval

*Weeks ${ }^{1}$ Tukey Test

0.01) [22]. Elmallah et al. clearly showed the highest specific cost occurred when using barbed wire [23].

Studies have shown that the use of barbed wire in skin sutures leads to a greater risk of adverse effects compared to other materials. However, few studies have specifically evaluated the superficial closure, as proposed in this study. According to a review of the literature presented by Fauor et al., only four studies compared the complications in skin closure with barbed wire and conventional techniques; these authors observed that most of the studies used the barbed wire in the deep closures [20]. Campbell et al. presented higher rates of superficial and deep infection $\left(\mathrm{p}^{<} 0.01\right)$ in patients undergoing skin stricture with barbed wire compared to staples, and two of the patients in the barbed wire group required complete revision of the arthroplasty [24]. Chawla et al. also concluded that patients submitted to barbed wire closure have a higher risk of superficial infection [25]. Corroborating with these findings, in our study, the patients in the barbed suture group had pain of greater intensity in the postoperative period, besides one patient who had superficial infection, and most of the dehiscences affected the patients of this group. The overtightening of barbed suture may predispose to less mobility between the cutaneous edges of the operative wound, resulting in greater tension during flexion and extension of the knee, leading to greater pain intensity compared to the other methods studied. It may also be a possible cause of ischemic cutaneous necrosis, resulting in dehiscence and superficial infection according to Campbell et al.[24].

The cosmetic appearance of the scar after any surgery is an important aspect of patient satisfaction, especially in women. Cosmetic evaluation, although very subjective, generally considers the color, width, and thickness of the scar, which, by the third month, shows a strongly predictive aspect of the long-term appearance, as concluded by Quinn et al. [26]. We used these concepts to guide the cosmesis analysis of the patients in the present study, where we evaluated the third month after surgery through the Stony Brook Scar scale that scores with the presence or absence of the following parameters: width greater than $2 \mathrm{~mm}$, elevation or depression, discoloration, suture or staple marks, and overall poor appearance, with 5 being the maximum cosmetic value and 0 being the worst evaluation [15]. Gililland et al. [10] and Ting et al. [22] did not find a difference between the traditional and barbed wire techniques using a tool to evaluate the cosmetic appearance of the surgical scar to the level of patient satisfaction using the Hollander Wound Evaluation Score, which uses parameters close to that of Stony Brook Scar scale. In the present study, we found better cosmetic results in the subcuticular suture groups, either with $M o n o c r y l^{\circ}$ or barbed Stratafix ${ }^{\circ}$ wire, compared to the single interrupted suture with MonoNylon ${ }^{\circ}$ group. The presence of darker staining and marks are very common aspects of the simple unabsorbable interrupted sutures that possibly led to a worse evaluation of the cosmesis in relation to the other two techniques.

This study has limitations that should be considered. First, the casuistry was small, so the conclusions reached can generate some insecurity. Secondly, the experience of the surgeon who performed the cutaneous closure in the conventional technique with simple suture was greater than in the other techniques, which may have led to bias in the evaluation of the closing time. In addition, use of unidirectional wires, which is different

Table 6 Analysis of the cosmesis score between groups, according Stony Brook Scar scale

\begin{tabular}{|c|c|c|c|c|c|c|c|}
\hline Group & Min. & Max. & Mean & $\pm S D$ & $95 \% \mathrm{Cl}$ & Group x Group & $\overline{p^{7}}$ \\
\hline Simple $^{\circledast}$ & 0 & 4 & 1.91 & 1.23 & {$[1.36-2.45]$} & Simple $\times$ Stratafix ${ }^{\oplus}$ & 0.00 \\
\hline Monocry $\left.\right|^{\circledast}$ & 1 & 5 & 3.30 & 1.03 & {$[2.82-3.78]$} & Monocry $\left.\right|^{\oplus} \times$ Simple & 0.01 \\
\hline Stratafix ${ }^{\circledast}$ & 0 & 5 & 3.00 & 1.30 & {$[2.41-3.60]$} & Stratafix ${ }^{\otimes} \times$ Monocryl $^{\oplus}$ & 0.70 \\
\hline
\end{tabular}

Min. minimum; Max. maximum; SD Standard deviation; $\mathrm{Cl}$ Confidence interval

${ }^{1}$ Tukey Test 
Table 7 Analysis of the complication between groups

\begin{tabular}{lllll}
\hline Group & $\mathbf{n}$ & Allergic reaction & Superficial infection & Slight dehiscence \\
\hline Simple & 22 & - & - & - \\
Monocry $^{\otimes}$ & 20 & - & - & 4 \\
Stratafix $^{\oplus}$ & 21 & - & 1 & 6 \\
\hline
\end{tabular}

$n$ number of patients.

to several other authors who used two-way barbed wire, and the use of two surgeons during skin closure, as reported by Smith et al. [12] could be a possible limitation. And finally, the cosmetic evaluation had very subjective aspects, which could result in an inaccurate analysis of the results.

\section{Conclusions}

This study concluded that continuous subcuticular suture with absorbable monofilament Monocryl ${ }^{\circ}$ proved advantageous in relation to the barbed Stratafix ${ }^{\circ}$ and monofilamentar unabsorbable MonoNylon ${ }^{\circ}$ single suture, which presented with equal or superior results in pain intensity, esthetic result, and cost effectiveness.

\section{Abbreviations}

TKA: Total Knee Arthroplasty; BMI: Body Mass Index

\section{Acknowledgements}

Not applicable.

\section{Authors' contributions}

RBV performed the surgeries TKA. RBV and TGC performed conception and design of the study. GWS and GBM performed acquisition and analysis of data. PAMM, JSF and JSV performed revising the study critically. All authors read and approved the final manuscript.

\section{Funding}

The authors declare that there was no source of funding acquired for this study.

\section{Availability of data and materials}

The datasets used and/or analysed during the current study are available from the corresponding author on reasonable request.

\section{Declarations}

Ethics approval and consent to participate

The study protocol was approved by Ethical Board of Faculdade de Ciências Médicas de Minas Gerais (CAAE45379515600005134. Approval date 08/24/ 2015). The study was 'retrospectively registered' on $07 / 29 / 2020$ by Brazilian Register Trials Number RBR78dh5d according WHO ICTRP.

All participants signed written informed consent.

\section{Consent for publication}

Not applicable.

\section{Competing interests}

The authors declare that they have no competing interests.
Received: 27 May 2020 Accepted: 18 August 2021

Published online: 30 August 2021

\section{References}

1. Kurtz S, Ong K, Lau E, Mowat F, Halpern M. Projections of primary and revision hip and knee arthroplasty in the United States from 2005 to 2030. J Bone Jt Surg. 2007;89:780. doi:https://doi.org/10.2106/JBJS.F.00222.

2. Lau RL, Gandhi R, Mahomed S, Mahomed N. Patient satisfaction after total knee and hip arthroplasty. Clin Geriatr Med. 2012;28:349-65. doi:https://doi. org/10.1016/j.cger.2012.05.001.

3. Krebs VE, Elmallah RK, Khlopas A, Chughtai M, Bonutti PM, Roche M, et al. Wound closure techniques for total knee arthroplasty: an evidence-based review of the literature. J Arthroplasty. 2018;33:633-8. doi:https://doi.org/1 0.1016/j.arth.2017.09.032.

4. Yuenyongviwat V, lamthanaporn $K$, Hongnaparak T, Tangtrakulwanich B. A randomised controlled trial comparing skin closure in total knee arthroplasty in the same knee: nylon sutures versus skin staples. Bone Joint Res. 2016;5:185-90. doi:https://doi.org/10.1302/2046-3758.55.2000629.

5. Smith TO, Sexton D, Mann C, Donell S. Sutures versus staples for skin closure in orthopaedic surgery: meta-analysis. BMJ. 2010;340:C1199.

6. Krishnan R, MacNeil SD, Malvankar-Mehta MS. Comparing sutures versus staples for skin closure after orthopaedic surgery: systematic review and meta-analysis. BMJ Open. 2016;6:e009257. doi:https://doi.org/10.1136/ bmjopen-2015-009257.

7. Duscher D, Pollhammer MS, Wenny R, Shamiyeh A, Schmidt M, Huemer GM Barbed sutures in body-contouring: outcome analysis of 695 procedures in 623 patients and technical advances. Aesthetic Plast Surg. 2016;40:815-21. doi:https://doi.org/10.1007/s00266-016-0701-2.

8. Abraham C. A randomized clinical trial of knotless barbed suture vs conventional suture for closure of the uterine incision at cesarean delivery. Am J Obstet Gynecol. 2018;219:220-1. doi:https://doi.org/10.1016/j.ajog.201 8.04.028.

9. Wang M, Mu X, Yang F, Niu Y, Xing N. Self-retaining barbed suture reduces warm ischemia time during laparoscopic partial nephrectomy. Minim Invasive Ther Allied Technol. 2018;27:272-7. doi:https://doi.org/10.1080/1364 5706.2018.1438473.

10. Gililland JM, Anderson LA, Sun G, Erickson JA, Peters CL. Perioperative closure-related complication rates and cost analysis of barbed suture for closure in TKA. Clin Orthop Relat Res. 2012;470:125-9. doi:https://doi.org/1 0.1007/s11999-011-2104-7.

11. Sah AP. Is there an advantage to knotless barbed suture in TKA wound closure? a randomized trial in simultaneous bilateral TKAs. Clin Orthop Relat Res. 2015;473:2019-27. doi:https://doi.org/10.1007/s11999-015-4157-5.

12. Smith EL, DiSegna ST, Shukla PY, Matzkin EG. Barbed versus traditional sutures: closure time, cost, and wound related outcomes in total joint arthroplasty. J Arthroplasty. 2014;29:283-7. doi:https://doi.org/10.1016/j.arth.2 013.05.031.

13. Austin DC, Keeney BJ, Dempsey BE, Koenig KM. Are barbed sutures associated with 90-day reoperation rates after primary TKA? Clin Orthop Relat Res. 2017;475:2655-65. doi:https://doi.org/10.1007/s11999-017-5474-7.

14. Meena S, Gangary S, Sharma P, Chowdhury B. Barbed versus standard sutures in total knee arthroplasty: a meta-analysis. Eur J Orthop Surg Traumatol. 2015;25:1105-10. doi:https://doi.org/10.1007/s00590-015-1644-z.

15. Singer AJ, Arora B, Dagum A, Valentine S, Hollander JE. Development and validation of a novel scar evaluation scale. Plast Reconstr Surg. 2007;120: 1892-7. doi:https://doi.org/10.1097/01.prs.0000287275.15511.10.

16. Chan WWK, Chan P-K, Chiu K-Y, Yan C-H, Ng F-Y. Does barbed suture lower cost and improve outcome in total knee arthroplasty? A randomized controlled trial. J Arthroplasty. 2017;32:1474-7. doi:https://doi.org/10.1016/j.a rth.2016.12.015. 
17. Cross M, Smith E, Hoy D, Nolte S, Ackerman I, Fransen M, et al. The global burden of hip and knee osteoarthritis: estimates from the Global Burden of Disease 2010 study. Ann Rheum Dis. 2014;73:1323-30. doi:https://doi.org/1 0.1136/annrheumdis-2013-204763.

18. Kuroki LM, Mullen MM, Massad LS, Wu N, Liu J, Mutch DG, et al. Wound complication rates after staples or suture for midline vertical skin closure in obese women. Obstet Gynecol. 2017;130:91-9. doi:https://doi.org/10.1097/A OG.0000000000002061.

19. Borzio RW, Pivec R, Kapadia BH, Jauregui JJ, Maheshwari AV. Barbed sutures in total hip and knee arthroplasty: what is the evidence? A meta-analysis. Int Orthop. 2016:40:225-31. doi:https://doi.org/10.1007/s00264-015-3049-3.

20. Faour M, Khlopas A, Elmallah RK, Chughtai M, Kolisek FR, Barrington JW, et al. The role of barbed sutures in wound closure following knee and hip arthroplasty: a review. J Knee Surg. 2018;31:858-65. doi:https://doi.org/10.1 055/s-0037-1615812.

21. Maheshwari AV, Naziri Q, Wong A, Burko I, Mont MA, Rasquinha VJ. Barbed sutures in total knee arthroplasty: are these safe, efficacious, and costeffective? J Knee Surg. 2015;28:151-6. doi:https://doi.org/10.1055/s-0034-13 73741.

22. Ting NT, Moric MM, Della Valle CJ, Levine BR. Use of knotless suture for closure of total hip and knee arthroplasties: a prospective, randomized clinical trial. J Arthroplasty. 2012;27:1783-8. doi.https://doi.org/10.1016/j.a rth.2012.05.022.

23. Elmallah RK, Khlopas A, Faour M, Chughtai M, Malkani AL, Bonutti PM, et al. Economic evaluation of different suture closure methods: barbed versus traditional interrupted sutures. Ann Transl Med. 2017;5:26. doi:https://doi. org/10.21037/atm.2017.08.21.

24. Campbell AL, Patrick DA, Liabaud B, Geller JA. Superficial wound closure complications with barbed sutures following knee arthroplasty. J Arthroplasty. 2014;29:966-9. doi:https://doi.org/10.1016/j.arth.2013.09.045.

25. Chawla $H$, van der List JP, Fein NB, Henry MW, Pearle AD. Barbed suture is associated with increased risk of wound infection after unicompartmental knee arthroplasty. J Arthroplasty. 2016;31:1561-7. doi:https://doi.org/10.101 6/j.arth.2016.01.007.

26. Quinn J, Wells G, Sutcliffe T, Jarmuske M, Maw J, Stiell I, et al. Tissue adhesive versus suture wound repair at 1 year: randomized clinical trial correlating early, 3-month, and 1-year cosmetic outcome. Ann Emerg Med. 1998;32:645-9

\section{Publisher's Note}

Springer Nature remains neutral with regard to jurisdictional claims in published maps and institutional affiliations.

Ready to submit your research? Choose BMC and benefit from:

- fast, convenient online submission

- thorough peer review by experienced researchers in your field

- rapid publication on acceptance

- support for research data, including large and complex data types

- gold Open Access which fosters wider collaboration and increased citations

- maximum visibility for your research: over $100 \mathrm{M}$ website views per year

At $\mathrm{BMC}$, research is always in progress.

Learn more biomedcentral.com/submissions 